\title{
Development of the Murine Tubotympanal Cavity
}

\author{
Keehyun Park, MD ${ }^{1}$, Myung-Hyun Chung, MD ${ }^{1}$, Byoung-Kil Hwang, MD ${ }^{1}$, \\ Young Myoung Kim, $\mathrm{MD}^{2}$ and David J, Lim, $\mathbf{M D}^{3}$ \\ ${ }^{I}$ Department of Otolaryngology, Yonsei University College of Medicine, Seoul; and ${ }^{2}$ Department of Otolaryngology, College of Medicine, \\ Ewha Woman's University, Seoul, Korea; and ${ }^{3}$ National Institute of Deafness and Other Communication Disorder, Bethesda, USA
}

Korean Journal of Otolaryngology-Head and Neck Surgery 1993;36(4):583-92.

The following original article from Korean Journal of Otolaryngology-Head and Neck Surgery, "Development of the Murine Tubotympanal Cavity" by Keehyun Park, published on April 1993 has been withdrawn from publication by agreement among the authors, the journal Editor, Sung Won Chae, and the publisher ML communications Co., Ltd. The retraction has been agreed due to substantial overlap of the content of this article with previously published one. The author and the Journal apologize to readers.

Sung Won Chae, MD, PhD

Editor

Korean Journal of Otorhinolaryngology-Head and Neck Surgery 